\title{
Differential Regulation of Bladder Pain and Voiding Function by Sensory Afferent Populations Revealed by Selective Optogenetic Activation
}

\author{
Jennifer J. DeBerry ${ }^{1 \dagger}$, Vijay K. Samineni ${ }^{2 \dagger}$, Bryan A. Copits ${ }^{2}$, Christopher J. Sullivan ${ }^{3}$, \\ Sherri K. Vogt ${ }^{2}$, Kathryn M. Albers ${ }^{3,4}$, Brian M. Davis ${ }^{3,4 *}$ and Robert W. Gereau IV ${ }^{2 *}$ \\ ${ }^{1}$ Department of Anesthesiology and Perioperative Medicine, University of Alabama at Birmingham, Birmingham, AL, \\ United States, ${ }^{2}$ Department of Anesthesiology, Washington University Pain Center, St. Louis, MO, United States, \\ ${ }^{3}$ Department of Neurobiology, Center for Neuroscience at the University of Pittsburgh, Pittsburgh, PA, United States, \\ ${ }^{4}$ Pittsburgh Center for Pain Research, Center for Neuroscience at the University of Pittsburgh, Pittsburgh, PA, United States
}

\section{OPEN ACCESS}

Edited by: Jyoti N. Sengupta, Medical College of Wisconsin, United States

Reviewed by: David I. Hughes, University of Glasgow,

United Kingdom Joel Charles Geerling, University of lowa Hospitals and Clinics, United States

${ }^{*}$ Correspondence: Brian M. Davis bmd1@pitt.edu Robert W. Gereau IV gereaur@wustl.edu

${ }^{\dagger}$ These authors have contributed equally to this work.

Received: 18 October 2017 Accepted: 23 January 2018 Published: 12 February 2018

Citation:

DeBerry JJ, Samineni VK, Copits BA

Sullivan CJ, Vogt SK, Albers KM, Davis BM and Gereau RW IV

(2018) Differential Regulation of Bladder Pain and Voiding Function by Sensory Afferent Populations Revealed by Selective Optogenetic Activation.

Front. Integr. Neurosci. 12:5. doi: 10.3389/fnint.2018.00005
Bladder-innervating primary sensory neurons mediate reflex-driven bladder function under normal conditions, and contribute to debilitating bladder pain and/or overactivity in pathological states. The goal of this study was to examine the respective roles of defined subtypes of afferent neurons in bladder sensation and function in vivo via direct optogenetic activation. To accomplish this goal, we generated transgenic lines that express a Channelrhodopsin-2-eYFP fusion protein (ChR2-eYFP) in two distinct populations of sensory neurons: TRPV1-lineage neurons (Trpv1 ${ }^{\mathrm{Cre}}$;Ai32, the majority of nociceptors) and $\mathrm{Na}_{v} 1.8^{+}$neurons (Scn10a ${ }^{\mathrm{Cre}}$;Ai32, nociceptors and some mechanosensitive fibers). In spinal cord, eYFP+ fibers in Trpv1 ${ }^{\mathrm{Cre}}$;Ai32 mice were observed predominantly in dorsal horn (DH) laminae I-II, while in Scn10aCre;Ai32 mice they extended throughout the $\mathrm{DH}$, including a dense projection to lamina $\mathrm{X}$. Fiber density correlated with number of retrogradely-labeled eYFP+ dorsal root ganglion neurons (82.2\% Scn10aCre;Ai32 vs. 62\% Trpv1 ${ }^{\mathrm{Cre}}$;Ai32) and degree of DH excitatory synaptic transmission. Photostimulation of peripheral afferent terminals significantly increased visceromotor responses to noxious bladder distension $(30-50 \mathrm{mmHg}$ ) in both transgenic lines, and to non-noxious distension $(20 \mathrm{mmHg}$ ) in Scn10aCre;Ai32 mice. Depolarization of $\mathrm{ChR} 2+$ afferents in $\mathrm{Scn} 10 a^{\mathrm{Cre}}$;Ai32 mice produced low- and high-amplitude bladder contractions respectively in 53\% and $27 \%$ of stimulation trials, and frequency of high-amplitude contractions increased to $60 \%$ after engagement of low threshold (LT) mechanoreceptors by bladder filling. In Trpv $1^{\text {Cre }}$;Ai32 mice, low-amplitude contractions occurred in $27 \%$ of trials before bladder filling, which was pre-requisite for light-evoked high-amplitude contractions (observed in $53.3 \%$ of trials). Potential explanations for these observations include physiological differences in the thresholds of stimulated fibers and their connectivity to spinal circuits.

Keywords: micturition, voiding, interstitial cystitis, TRPV1, $\mathrm{Na}_{\mathrm{v}} 1.8$, visceral, optogenetics, channelrhodopsin 


\section{INTRODUCTION}

The urinary bladder is innervated by primary sensory neurons with somata in the dorsal root ganglia (DRG) giving rise to lightly-myelinated (A $\delta)$ or unmyelinated (C) axons, the majority of which are polymodal mechanosensors (Sengupta and Gebhart, 1994a; Su et al., 1997; Shea et al., 2000). Polymodal mechanosensitive bladder afferents fall into low threshold (LT) and high threshold (HT) categories, distinguishable by their response to luminal distension (Sengupta and Gebhart, 1994a,b). In contrast to cutaneous sensory neurons, response threshold and fiber type of visceral sensory neurons do not correlate (Sengupta and Gebhart, 1994a; Su et al., 1997; Shea et al., 2000). Visceral LT afferents have extrapolated thresholds that are less than one-tenth the threshold of HT afferents, but LT afferents can code noxious distension pressures by increasing firing rate up to twice the frequency seen at threshold. Thus, both LT and HT visceral sensory neurons may be defined as nociceptors.

Pathological changes in bladder sensation often manifest as increased urinary frequency, with pain or without pain, as seen in interstitial cystitis (IC) and overactive bladder $(\mathrm{OAB})$, respectively. Efficacious treatment strategies for stratified patient groups require an understanding of the physiological, molecular, and anatomical sensory components that differentiate bladder function and pain. Animal studies of bladder sensation that have utilized neurotoxins to desensitize C-fiber afferents suggest that mechanosensitive $\mathrm{A} \delta$-fiber bladder afferents are responsive to physiologic changes in intravesical pressure (IVP) during normal bladder filling, while polymodal C-fiber afferents are "recruited" during noxious stimulation or tissue injury (Mallory et al., 1989; Cheng et al., 1993, 1995). However, other studies have shown both loss- and gain-offunction bladder phenotypes in mice following antagonism or knockout of transient receptor potential cation channel subfamily V, member 1 (TRPV1; Birder et al., 2002; Daly et al., 2007; Charrua et al., 2009; Yoshiyama et al., 2015), a non-specific cation channel that is preferentially expressed on peptidergic C-fiber afferents (Michael and Priestley, 1999; Leffler et al., 2006; Cavanaugh et al., 2011a). Additional studies that have manipulated the expression or function of $\mathrm{Na}_{\mathrm{v}} 1.8$, a TTX-resistant voltage-gated sodium channel expressed by a combination of myelinated and unmyelinated afferents including putative C-low-threshold mechanoreceptors (CLTMs; Shields et al., 2012) have demonstrated changes in both normal and pathological bladder sensation (Yoshimura et al., 2001; Laird et al., 2002). It is unclear whether changes in bladder sensation observed in these studies are due to the loss of specific channel activity vs. altered function in the afferent populations in which they are expressed.

Optogenetics combines genetic and optical technologies to directly excite or inhibit genetically defined cells with spatial and temporal precision (Boyden et al., 2005). The excitatory opsin, channelrhodopsin-2 (ChR2), is a blue light ( $\sim 70 \mathrm{~nm}$ )-sensitive ion channel, opening of which causes transducer-independent depolarization and action potential firing in ChR2-expressing neurons. Recent studies demonstrate that activation of ChR2-expressing sensory neurons can evoke nocifensive behaviors in mice (Daou et al., 2013; Boada et al., 2014; Iyer et al., 2014; Baumbauer et al., 2015; Montgomery et al., 2015; Park et al., 2015; Copits et al., 2016; Samineni et al., 2017b). The aim of the current study was to use an in vivo, direct method of neuronal stimulation, unbiased by dependence on mechanical or chemical transduction, to determine whether distinct components of bladder sensation that relate to nociception vs. micturition are intrinsically contributed by defined populations of bladder afferent neurons. To achieve this, we utilized a Cre-lox recombination approach to express Channelrhodopsin-2-eYFP fusion protein (ChR2-eYFP) in lineage Trpv1- and Scn10a-expressing sensory neurons. We found that optical stimulation of the peripheral terminals of ChR2-expressing bladder primary sensory neurons increased nociceptive reflex behavior to mechanical distension of the bladder in both $\operatorname{Trpv} 1^{\mathrm{Cre}}$;Ai32 and $\mathrm{Scn}_{10 a^{\mathrm{Cre}}}$;Ai32 mice. However, optical stimulation of the two populations had differential effects on cystometric measures of bladder function.

\section{MATERIALS AND METHODS}

\section{Animals}

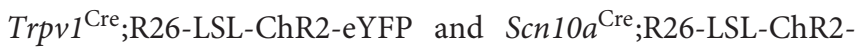
eYFP mice were bred by crossing female Ai32 mice (The Jackson Laboratory, stock \#024109) heterozygous or homozygous for the Rosa-CAG-LSL-ChR2(H134R)-eYFP-WPRE conditional allele with a loxP-flanked STOP cassette preventing transcription of the ChR2(H134R)-eYFP fusion gene (Madisen et al., 2012) with male Cre recombinase-expressing $\mathrm{BAC}$ transgenic mice. $\operatorname{Trpv1} 1^{\text {Cre }}$ mice (The Jackson Laboratory, stock \#017769) were used to target ChR2-eYFP expression to lineage Trpv1+ neurons, comprising virtually all C-fiber afferents (Cavanaugh et al., 2009, 2011b; Mishra et al., 2011). SNS ${ }^{\mathrm{Cre}}$ mice that express Cre recombinase under the regulatory elements of the Scn10a gene (Agarwal et al., 2004), which encodes the TTX-resistant $\mathrm{Na} 1.8$ sodium channel, were used to target ChR2-eYFP to a combination of C- and A $\delta$-fiber afferents (Shields et al., 2012). It should be noted that in SNS ${ }^{\mathrm{Cre}}$ (referred to hereafter as $\mathrm{Scn} 10 a^{\mathrm{Cre}}$ ) mice, expression of Cre is observed in all $\mathrm{Na}_{\mathrm{v}} 1.8+$ neurons, but not all Cre-expressing cells express $\mathrm{Na}_{\mathrm{v}} 1.8$ in adult mice (Liu et al., 2010; Shields et al., 2012; Chiu et al., 2014). As such, expression of ChR2 in adult mice is not $\mathrm{Na}_{\mathrm{v}} 1.8$ or Trpv1 "specific". We recently reported a characterization of the expression pattern of ChR2-eYFP in sensory neurons in the same mouse lines used here to generate ChR2 expression driven by the $\operatorname{Scn} 10 a^{\mathrm{Cre}}$ and $\operatorname{Trp} v 1^{\mathrm{Cre}}$ mice (Park et al., 2015). Female offspring harboring a cre transgene and that were heterozygous for the Rosa-CAG-LSL-ChR2(H134R)-eYFP-WPRE allele were studied. Experiments were restricted to females due to difficulty in transurethral bladder cannulation without invasive surgical incision in males.

\section{Retrograde Labeling and Histology}

The number of retrogradely labeled L6 DRG neurons expressing the ChR2-eYFP fusion protein was determined in $\operatorname{Tr} p v 1^{\mathrm{Cre}} ; \mathrm{Ai} 32$ and $\mathrm{Scn} 10 a^{\mathrm{Cre}} ; \mathrm{Ai} 32$ mice. Mice $(n=3-4$ per 
group) were anesthetized with isoflurane and the bladder was isolated via a midline laparotomy under aseptic conditions. Three to five $5 \mu$ l injections of AlexaFluor 555 conjugated to the beta subunit of cholera toxin (CT $\beta-555$; Molecular Probes) were made into the bladder wall. Prior to injection, the needle was tunneled subserosally to prevent back flow from the injection site upon needle withdrawal, during which injection sites were swabbed. Abdominal incisions were sutured and mice recovered for $4-5$ days. We have previously applied CT $\beta$ onto the serosal surface of pelvic viscera and adjacent tissues and found an average of two CT $\beta$-positive cells in L6 ganglia (Christianson et al., 2006). For tissue harvest, mice were deeply anesthetized and perfused with $4 \%$ paraformaldehyde. L6 DRG were dissected, cryoprotected in 30\% sucrose, and sectioned $(16 \mu \mathrm{m})$ on a cryostat. Z-stacks were collected for each section at $20 \times$ and a maximum intensity projection was obtained using a Nikon A1R upright resonant scanning confocal microscope and Nikon Elements software. Images of Z-stacks were viewed in Adobe Photoshop employing the "Channels" feature to separate color components to determine which cells expressed eYFP and/or were retrogradely labeled by CT $\beta-555$. Using images of individual channels, cells with signals $\geq 5$ standard deviations above background fluorescence were considered positive and counted. At least three sections separated by a minimum of $50 \mu \mathrm{m}$ were analyzed in a blinded fashion for each ganglion.

\section{Photostimulation}

Optical stimulation was performed using a $473 \mathrm{~nm}, 150 \mathrm{~mW}$ diode-pumped solid-state (DPSS) laser. In visceromotor reflex (VMR) studies, a fiber optic (200 $\mu$ m diameter core; BFH48-200Multimode, NA 0.48; Thorlabs) was coupled to the laser and connected to the transurethral catheter via a Y-shaped connector. The fiber tip was positioned $0.1 \mathrm{~mm}$ beyond the tip of the catheter in the bladder lumen. Photostimulation was $10 \mathrm{~mW} / \mathrm{mm}^{2}$ maximal intensity except where noted for stimulation intensityresponse curves. For cystometric studies, photostimulation was delivered transabdominally at $50 \mathrm{~mW} / \mathrm{mm}^{2}$ maximal intensity.

\section{Dissociated Neuron Electrophysiology}

DRG were dissected from $\mathrm{Trpvl}^{\mathrm{Cre}}$;Ai32 and Scn10a ${ }^{\mathrm{Cre}}$;Ai32 mice in ice-cold $\mathrm{Ca}^{2+} / \mathrm{Mg}^{2+}$-free Hank's buffered saline solution (HBSS) containing $10 \mathrm{mM}$ HEPES. The tissue was digested with $45 \mathrm{U}$ papain (Worthington Biochemical) in HBSS+HEPES for $20 \mathrm{~min}$ at $37^{\circ} \mathrm{C}$, washed three times with $3 \mathrm{ml}$ of $\mathrm{HBSS}+\mathrm{HEPES}$ at $37^{\circ} \mathrm{C}$ and digested in collagenase $\left(1.5 \mathrm{mg} / \mathrm{ml}\right.$; Sigma) for an additional $20 \mathrm{~min}$ at $37^{\circ} \mathrm{C}$. DRG were rinsed with HBSS+HEPES and mechanically dissociated by gentle trituration in Neurobasal A medium (Gibco) containing $5 \%$ fetal bovine serum (Life Technologies), $2 \mathrm{mM}$ GlutaMAX (Life Technologies), $1 \times$ B27 supplement (Gibco), and $100 \mathrm{U} / \mathrm{ml}$ penicillin/streptomycin (Life Technologies). The DRG suspension was filtered using a $40 \mu \mathrm{m}$ nylon filter, centrifuged $(1000 \mathrm{~g})$ for $3 \mathrm{~min}$, resuspended and then centrifuged $(1000 \mathrm{~g})$ an additional $3 \mathrm{~min}$. Cells were resuspended in medium and seeded on glass coverslips pre-coated with collagen and poly-D-lysine (Sigma). Cells were incubated at $37^{\circ} \mathrm{C}$ with $5 \% \mathrm{CO}_{2}$ for $72 \mathrm{~h}$ before electrophysiological recordings.

\section{Spinal Cord Slice Electrophysiology}

Transverse spinal cord slices were prepared from 6 week to 8 week old $\operatorname{Tr} p v 1^{\mathrm{Cre}} ; \mathrm{Ai} 32$ and $\operatorname{Scn} 10 a^{\mathrm{Cre}} ; \mathrm{Ai} 32$ mice using a protective cutting method (Ting et al., 2014). Animals were deeply anesthetized with ketamine/xylazine and transcardially perfused with room temperature NMDG-substituted aCSF containing (in $\mathrm{mM}$ ): $93 \mathrm{~N}$-methyl-D-glucamine, $2.5 \mathrm{KCl}$, $1.25 \mathrm{NaH}_{2} \mathrm{PO}_{4}, 30 \mathrm{NaHCO}_{3}, 20$ HEPES, 25 glucose, 5 ascorbic acid, 2 thiourea, 3 sodium pyruvate, $12 \mathrm{~N}$-acetyl-L-cysteine, $0.5 \mathrm{CaCl}_{2}, 10 \mathrm{MgSO}_{4}$ (pH to 7.3 with $\mathrm{HCl} ; 300-305 \mathrm{mOsm}$ ). A ventral laminectomy was performed to extract the spinal cord, and nerve roots and overlying dura mater were carefully removed. Lumbosacral (LS) segments were embedded in $2 \%$ low-melting agarose (Sigma; A6013) dissolved in NMDG solution. $350 \mu \mathrm{m}$ thick slices were cut using a Vibratome VT1000s (Leica) at room temperature, and transferred to an oxygenated recovery chamber containing NMDG-aCSF for $10-12 \mathrm{~min}$ at $32-34^{\circ} \mathrm{C}$. Slices were then moved to a holding chamber containing oxygenated aCSF, comprised of (in $\mathrm{mM}$ ): $124 \mathrm{NaCl}, 2.5 \mathrm{KCl}, 1.25 \mathrm{NaH}_{2} \mathrm{PO}_{4}, 24 \mathrm{NaHCO}_{3}, 5$ HEPES, 12.5 glucose, $2 \mathrm{CaCl}_{2}, 1 \mathrm{MgCl}_{2}$ ( $\left.\mathrm{pH}=7.3,300-305 \mathrm{mOsm}\right)$ and kept for up to $8 \mathrm{~h}$. Slices were transferred to the chamber of an upright Olympus BX-51 microscope and perfused continuously with oxygenated room temperature aCSF at $\sim 2 \mathrm{ml} / \mathrm{min}$. Spinal cord lamina were identified with a $4 \times$ objective, and the laminar position of all neurons was confirmed after recordings. Dorsal horn $(\mathrm{DH})$ neurons were visualized through a $40 \times$ objective using IR-DIC microscopy. Whole-cell patch-clamp recordings were performed using thick-walled borosilicate glass pipettes with resistance values of 3-5 $\mathrm{M} \Omega$, when filled with (in $\mathrm{mM}$ ): $105 \mathrm{CsMeSO}_{3}, 15 \mathrm{CsCl}, 8 \mathrm{NaCl}, 0.2$ EGTA, 10 HEPES, 4 MgATP, $0.4 \mathrm{Na}_{2} \mathrm{GTP}, 10$ sodium phosphocreatine, 10 tetraethylamine chloride, 3 QX314 chloride ( $\mathrm{pH}=7.3$ with $\mathrm{CsOH}, 291 \mathrm{mOsm}$ ). Recordings were made using Patchmaster software controlling a HEKA EPC10 amplifier. After gigaseal formation and stable whole-cell access, EPSCs were elicited from ChR2-expressing primary afferent fibers with $1 \mathrm{~ms}$ pulses of $470 \mathrm{~nm}$ blue light (Thorlabs; M470L2) delivered at $0.05 \mathrm{~Hz}$. Whole field illumination was achieved using a custom-made LED set-up with Köhler illumination, coupled to the back fluorescent port of the microscope. Light intensity was calibrated to be $10 \mathrm{~mW} / \mathrm{mm}^{2}$ at the surface of the slice using a photodiode (Thorlabs; S120C) and power meter (Thorlabs; PM100D). Neurons were voltage clamped at $-70 \mathrm{mV}$ and series resistance was compensated at $60 \%$ for all recordings. Series resistance values were $<30 \mathrm{M} \Omega$, and recordings were discarded if they changed by more than $20 \%$.

\section{Visceromotor Reflex Behavior}

The VMR, quantified using abdominal electromyograph (EMG) responses, is a reliable behavioral index of visceral nociception in rodents (Ness et al., 1991, 2001; Castroman and Ness, 2001; Crock et al., 2012; DeBerry et al., 2015). EMG responses to phasic urinary bladder distension (UBD) were recorded in lightly anesthetized, $\operatorname{Tr} p v 1^{\mathrm{Cre}} ; \mathrm{Ai} 32$ and $\mathrm{Scn} 10 a^{\mathrm{Cre}} ; \mathrm{Ai} 32$ mice. Mice were anesthetized with inhaled isoflurane (2\% in oxygen) and silver wire electrodes were placed in the oblique abdominal muscle and subcutaneously across the abdominal wall (as a 
ground) to allow differential amplification of abdominal EMG signals. A lubricated, 24-gauge angiocatheter was passed into the bladder via the urethra for UBD. After surgical preparation, isoflurane was reduced to $\sim 1 \%$ until a flexion reflex response was present (evoked by pinching the paw), but spontaneous escape behavior and righting reflex were absent. After the preferred level of anesthesia was attained, no adjustments were made to the isoflurane for the length of the experiment. Mice were not restrained in any fashion and body temperature was monitored and maintained at $37^{\circ} \mathrm{C}$ throughout the experiment using an overhead radiant light. UBD consisted of compressed air delivered via the transurethral catheter using a custom-made, automated distension control device (Washington University School of Medicine Electronic Shop). Phasic UBD consisted of graded distensions at pressures of $20-50 \mathrm{mmHg}$ (20 s duration; $3 \times$ each pressure, 5 min inter-trial interval). EMG signals were relayed in real time using a Grass P511 preamplifier (Grass Technologies) to a PC via a WinDaq DI-720 module (Dataq Instruments), and data were exported to Igor Pro 6.05 software (Wavemetrics). Baseline EMG activity was subtracted from EMG during UBD, rectified, and integrated to obtain distensionevoked EMG responses. Values reported represent the average of the three trials for each pressure. Distension-evoked EMG is presented as area under the curve.

\section{Cystometry}

Cystometrograms (CMGs) were performed in $\operatorname{Trpv1}{ }^{\mathrm{Cre}} ; \mathrm{Ai} 32$ and Scn $10 a^{\text {Cre }}$;Ai32 mice under urethane anesthesia $(1.25 \mathrm{~g} / \mathrm{kg}$, i.p.). A 24-gauge angiocathether was passed into the bladder lumen through the urethra for saline infusion and measurement of IVP via an in-line, low volume pressure transducer. A midline abdominal incision was made through the skin and rectus muscle and the tissues were gently retracted. The urinary bladder was isolated and periodically irrigated throughout the experiment. Approximately $20 \mathrm{~min}$ following urethane administration, saline infusion was initiated at a rate of $20 \mu \mathrm{L} / \mathrm{min}$ to elicit phasic detrusor contractions during bladder filling. After $15 \mathrm{~min}$ of recording ( $0.3 \mathrm{ml}$ total volume), saline infusion was stopped, the catheter was disconnected, and the bladder was emptied using manual compression of the lower abdomen (Credés maneuver). The catheter was reconnected to the infusion pump and transducer. Bladder contractile responses were then quantified in response to photostimulation $(1,2$ and $5 \mathrm{~s}$ of the empty bladder, and then again after saline was infused $(20 \mu \mathrm{L} / \mathrm{min})$ into the bladder to $80 \%$ of the micturition threshold (MT), defined as the intravesical volume immediately preceding the onset of the first contractile response of magnitude $\geq 7.5 \mathrm{mmHg}$ (Cockayne et al., 2000). Photostimulation was restricted to a $3 \mathrm{~mm}^{2}$ area of bladder tissue using an opaque shield. Body temperature was maintained at $37^{\circ} \mathrm{C}$ throughout surgical preparation and data collection using a heating pad placed underneath the animal. IVP was recorded continuously (Spike2 software, Cambridge Electrical Design). Baseline pressure was calculated as the average IVP over a $1 \mathrm{~min}$ period prior to saline infusion. Pressure threshold (PT) was defined as the IVP at the MT. Light stimulation-evoked $\Delta \mathrm{IVP}$ was calculated as the peak IVP after stimulus minus the IVP at stimulus onset.

\section{Statistical Analyses}

Data are presented as mean \pm SEM except where noted. Retrogradely labeled eYFP+ DRG neuron counts were compared by a Chi-square test and a Kolmogorov-Smirnov test was used to compare cumulative distributions of cell size. The VMR, quantified as abdominal EMG responses to graded UBD with and without concurrent photostimulation, was compared using a two-way ANOVA with repeated measures and Bonferroni post-tests. Baseline IVP, MT and PT were compared using $t$-tests. Differences in the presence of laserevoked bladder contractile activity were determined using Chi-square tests. Two-way ANOVAs were used to analyze the effects of stimulus duration on changes in IVP during empty and saline trials. EPSC amplitude and charge transfer during spinal cord recordings were compared with unpaired $t$-tests. A $P$-value of $<0.05$ was considered significant for all statistical comparisons.

\section{RESULTS}

\section{Peripheral and Central Projections of eYFP+ Fibers Are Differentially Distributed in Trpv1 ${ }^{\mathrm{Cre}}$;Ai32 and Scn 10aCre;Ai32 Mice}

Histological characterization of retrogradely labeled CT $\beta+$ neurons revealed numerous eYFP-expressing neurons projecting to the bladder from LS DRG in $\operatorname{Trpv1}^{\mathrm{Cr}} ;{ }^{\mathrm{Ci}} 32$

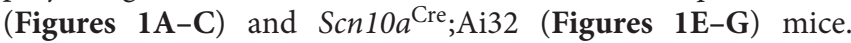
However, there were significantly more eYFP+ bladder neurons in $\mathrm{Scn} 10 a^{\mathrm{Cre}}$;Ai32 mice than in $\operatorname{Trpvl}^{\mathrm{Cre}} ; \mathrm{Ai} 32$ mice $(100 / 122$ vs. 107/172, respectively; Chi-square, $P<0.001$; $n=3-4$ /group). Cell area distributions (Figures $\mathbf{1 M}, \mathbf{N}$ ) show a wide range of labeled neurons. CT $\beta+$ eYFP-expressing neurons ranged from 79.60 to $953.12 \mu \mathrm{m}^{2}$ (mean $=314.41 \mu \mathrm{m}^{2}$, sd $=177.21 \mu \mathrm{m}^{2}$ ) in Scn10a ${ }^{\mathrm{Cre}}$;Ai32 mice and from 79.48 to $935.0 \mu \mathrm{m}^{2}\left(\right.$ mean $=367.18 \mu \mathrm{m}^{2}$, sd $\left.=184.66 \mu \mathrm{m}^{2}\right)$ in Trpv1 ${ }^{\text {Cre }}$;Ai32 mice with no significant difference between cumulative distributions (Kolmogorov-Smirnov test, $P=0.97)$.

ChR2+ DRG neurons from Trpv1 ${ }^{\mathrm{Cre}} ; \mathrm{Ai} 32$ and Scn $10 a^{\text {Cre }}$;Ai32 mice exhibited inward currents upon blue light illumination in voltage clamp recordings (Figures 1D,H), in accordance with our previous observations (Park et al., 2015). Examination of the LS spinal cord showed that eYFP-expressing fibers project to superficial and deep laminae of the spinal $\mathrm{DH}$, including all regions previously shown to receive projections from bladder afferents (Nadelhaft et al., 1992; Birder and de Groat, 1993), but we observed differences in terminal density in different spinal laminae. In $\operatorname{Trpv}^{\mathrm{Cre}} ; \mathrm{Ai} 32$ mice (Figure 1I), the heaviest distribution of eYFP+ terminals was in the most superficial layers of the DH (laminae I-II) and to a lesser degree in lamina $\mathrm{X}$ (dorsal commissure) with sparse projections to parasympathetic preganglionic neurons in the sacral parasympathetic nucleus (SPN; although recent articles argue that these cells have more in common with neurons in the sympathetic intermediolateral cell column (IML) found at T1-L2 spinal cord levels (Espinosa-Medina et al., 2016, 2017)). In 

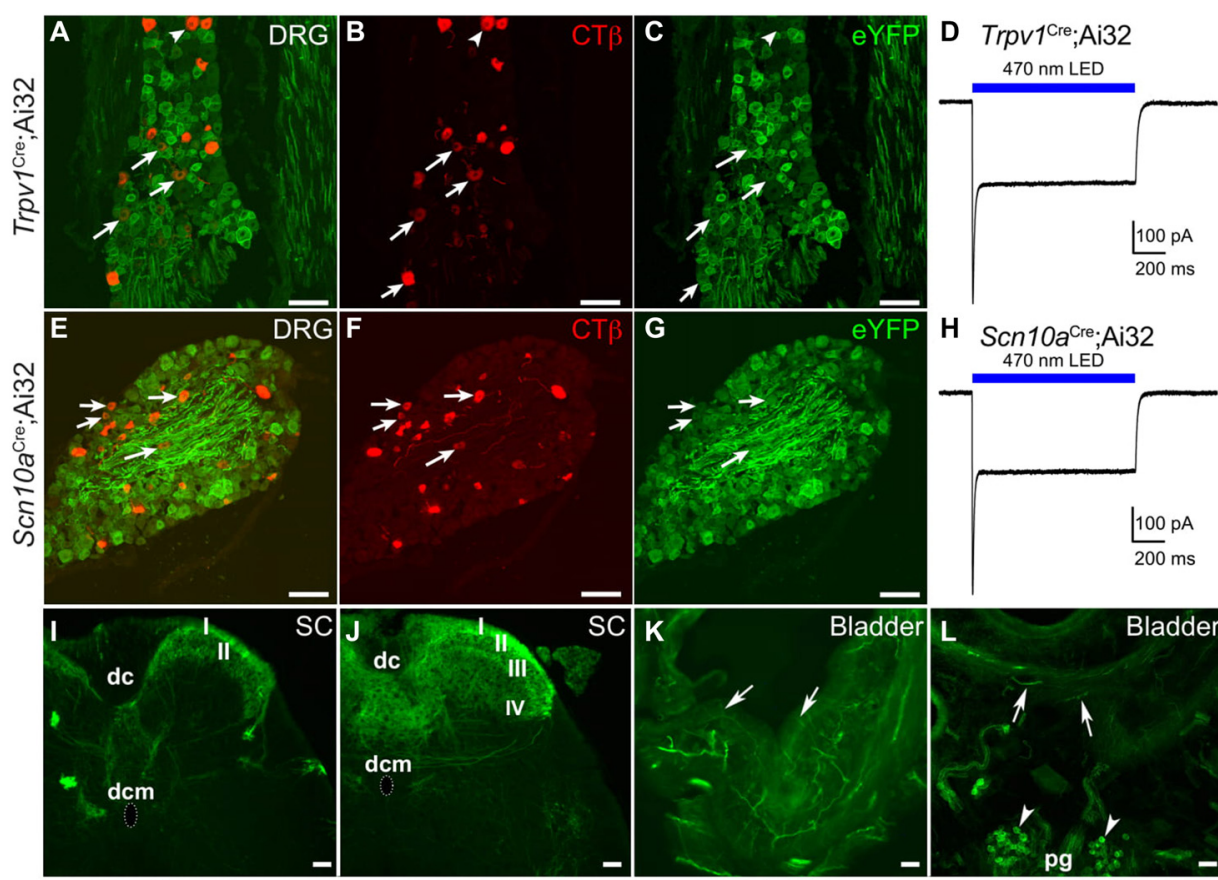

Trpv1 ${ }^{\text {Cre }} ; \mathrm{Ai} 32$

Scn10a ${ }^{\mathrm{Cre}} ; \mathrm{Ai} 32$

Trpv1 ${ }^{\text {Cre } ; A i 32 ~}$
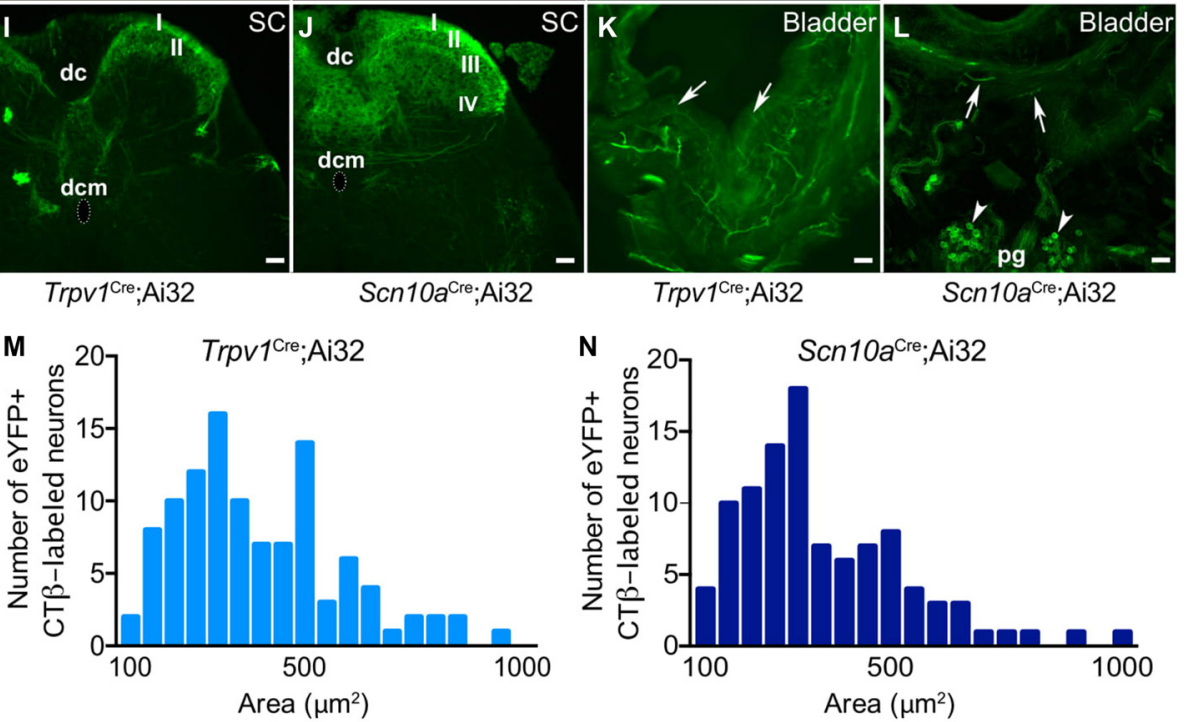

FIGURE 1 | Histological characterization of eYFP+ neurons in Trpv1 ${ }^{\text {Cre } ; A i 32 ~ a n d ~ S c n 10 a C r e ; A i 32 ~ m i c e . ~ H i s t o l o g i c a l ~ c h a r a c t e r i z a t i o n ~ o f ~ L 6-S 1 ~ d o r s a l ~ r o o t ~ g a n g l i a ~}$ (DRG) from Trpv1 ${ }^{\mathrm{Cre}}$;Ai32 (A-C) and Scn10a ${ }^{\mathrm{Cre}} ; \mathrm{Ai} 32$ (E-G) mice confirms eYFP reporter expression in bladder projecting CT $\beta+$ DRG neurons. Arrows indicate neurons that co-label for CT $\beta$ and eYFP. Voltage clamp recordings from isolated Trpv $1{ }^{\mathrm{Cre}}$;Ai32 (D) and Scn10aCre;Ai32 (H) ChR2+ DRG neurons show $1 \mathrm{~s}$ blue light stimulation resulted in inward current. (I) In $\operatorname{Trpv}^{\mathrm{Cre}}$;Ai32 mice, eYFP+ terminals were observed in the most superficial layers of the dorsal horn (DH; laminae I-II), and to a lesser degree in lamina X (dorsal commissure; $\mathrm{dcm}$ ) with sparse projections to the sacral parasympathetic nucleus. dc, dorsal columns. (J) In

Scn10a ${ }^{\text {Cre } ; A i 32 ~ m i c e, ~ d e n s e ~ e Y F P+~ a f f e r e n t ~ t e r m i n a l ~ d i s t r i b u t i o n ~ i s ~ o b s e r v e d ~ i n ~ l a m i n a e ~ I-V ~ a n d ~ X, ~ w i t h ~ v e r y ~ f e w ~ t e r m i n a l s ~ i n ~ t h e ~ s a c r a l ~ p a r a s y m p a t h e t i c ~ n u c l e u s . ~}$ $(\mathbf{K}, \mathbf{L})$ In bladder, tissue, eYFP+ fibers were seen in both mouse lines branching from large nerves at the base of the bladder and the outer muscular layers, coursing toward the lumen. Fibers often terminated in the urothelium in Trpv ${ }^{\text {Cre }}$;Ai32 mice. In Scn10a Cre; Ai32 mice, the parasympathetic postganglionic neurons (pg) at the base of the bladder also expressed eYFP (arrowheads). (M,N) Cumulative distributions of cell area for eYFP+ CTR-labeled neurons in Trpv ${ }^{\text {Cre }}$;Ai32 and

Scn10a ${ }^{\text {Cre }}$;Ai32 mice did not statistically differ (Kilmogorov-Smirnov test, $P=0.97, n=107$ for Trpv ${ }^{\text {Cre }}$;Ai32 and $n=100$ for Scn10a ${ }^{\text {Cre }}$;Ai32). Scale bars represent $100 \mu \mathrm{m}$ for (A-G) and $50 \mu \mathrm{m}$ for (I-L).

contrast, $\operatorname{Scn} 10 a^{\mathrm{Cre}}$;Ai32 mice exhibited dense afferent terminal distribution to laminae $\mathrm{I}-\mathrm{V}$ and $\mathrm{X}$, with very few terminals observed in the SPN (Figure 1J).

In bladder, eYFP+ fibers were seen in both $\operatorname{Trp} v 1^{\mathrm{Cre}} ; \mathrm{Ai} 32$ (Figure 1K) and $S c n 10 a^{\mathrm{Cre}}$;Ai32 (Figure 1L) mice, branching from large nerves at the base of the bladder and the outer muscular layers, coursing toward the lumen, and often terminating in the urothelium. In $\mathrm{Scn} 10 a^{\mathrm{Cre}}$;Ai32 mice, the parasympathetic postganglionic neurons found at the base of the bladder also expressed eYFP (Figure 1L).

\section{Optogenetic Stimulation of Defined Subpopulations of Bladder Afferent Terminals Modulates Bladder Nociception and Voiding}

Initially, optical stimulation was applied to the hind paw of lightly anesthetized ChR2-expressing mice to assess nocifensive responses. Light stimulation of the glabrous skin elicited a robust hind paw withdrawal-evoked abdominal EMG response (Figure 2A), consistent with previously published 

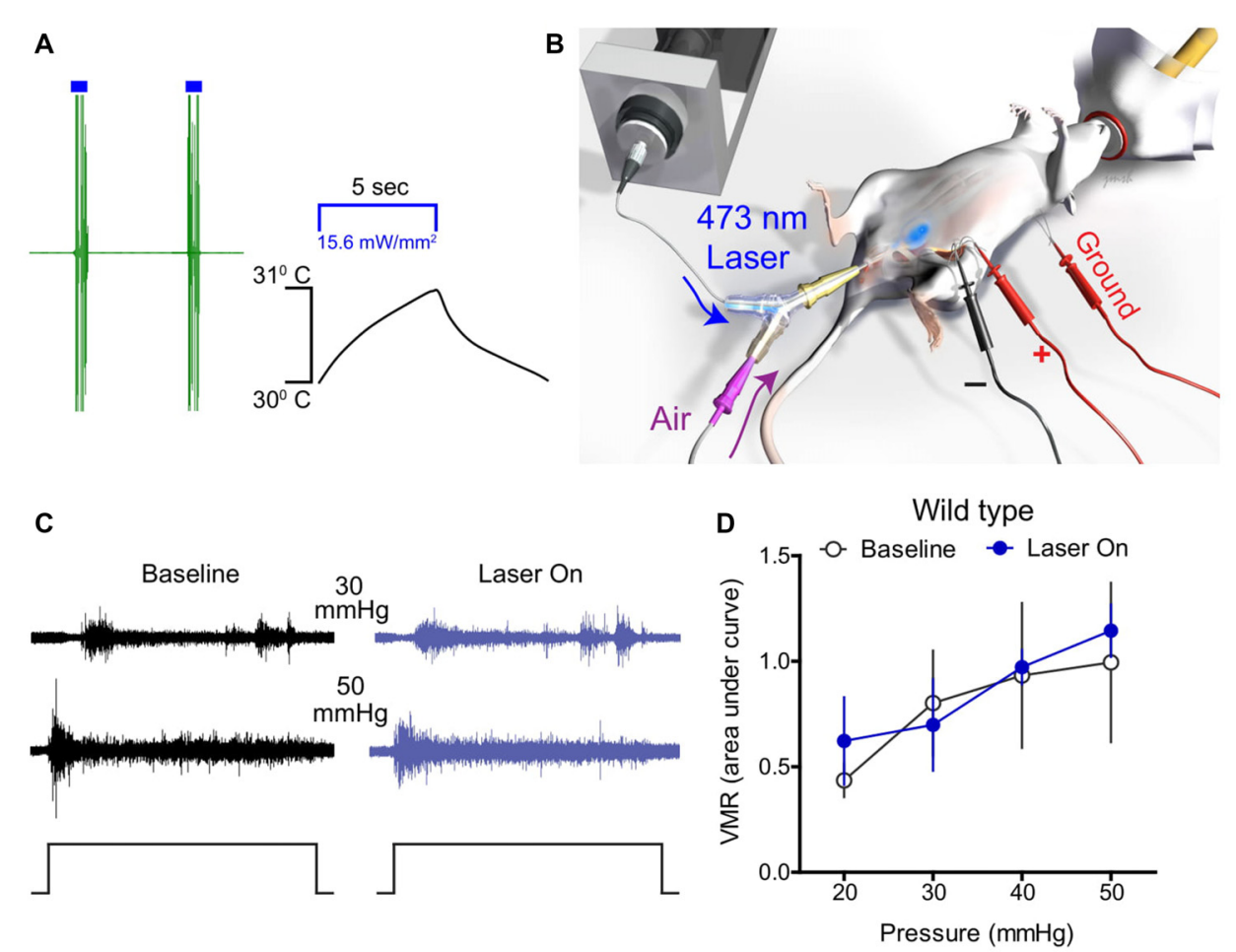

FIGURE 2 | Optical stimulation of bladder afferents did not change bladder distension-evoked responses in wild type mice. (A) A representative trace shows that optical stimulation of glabrous skin elicited a robust hind paw withdrawal-evoked abdominal electromyograph (EMG) response in ChR2-expressing mice. Thermistor measurements of skin temperature at the site of stimulation skin show that temperature did not increase more than $1^{\circ} \mathrm{C}$ upon laser illumination, suggesting that increased EMG activity was not a heat-evoked response. (B) Schematic depicting bladder distension, visceromotor reflex (VMR) recording, and optical stimulation setup. (C) Representative raw EMG traces from wild type mice during 30 and $50 \mathrm{mmHg}$ bladder distension before (baseline) and during (laser on) blue light stimulation. (D) Transurethral fiber optic delivery of blue light to the bladder lumen (laser on) did not affect the evoked response to bladder distension compared with baseline (pre-laser) responses in wild type mice $(P>0.05$, two-way ANOVA; $n=8$ mice).

studies (Ji et al., 2012; Baumbauer et al., 2015). Thermistor measurements of skin temperature at the site of stimulation suggest that this was not a heat-evoked response, since skin temperature did not increase more than $1^{\circ} \mathrm{C}$ upon exposure to the laser for $5 \mathrm{~s}$ (Figure 2A). To study whether optogenetic stimulation of peripheral bladder afferent terminals in $\operatorname{Trp} v 1^{\mathrm{Cre}}$;Ai32 and Scn10a ${ }^{\mathrm{Cre}}$;Ai32 mice could evoke or modulate nociceptive reflex behaviors, VMR recordings during graded UBD in conjunction with transurethral laser stimulation were performed (Figure 2B). Graded UBD produced pressure-dependent increases in VMRs in wild type mice that were not altered by laser stimulation $(n=8$; two-way ANOVA, $F_{(1,42)}=0.10, P>0.05$; Figures 2C,D). In contrast, concurrent transurethral laser stimulation significantly increased UBD-evoked VMRs in both $\operatorname{Trpv} 1^{\mathrm{Cre}}$;Ai32 mice $(n=8$; two-way ANOVA, $F_{(1,42)}=17.71, P<0.01$; Figures 3A,C) and Scn10a ${ }^{\mathrm{Cre}}$;Ai32 mice $\left(n=8\right.$; two-way ANOVA, $F_{(1,42)}=8.76$, $P<0.01$; Figures 3B,E). Interestingly, laser stimulation significantly increased VMRs in both groups during noxious distension (30-50 mmHg; all $P$ values $<0.05$ ), but only in $\mathrm{Scn} 10 a^{\mathrm{Cre}}$;Ai32 mice during non-noxious distension $(20 \mathrm{mmHg}$; $P<0.05$ ). Laser power of $\geq 0.1 \mathrm{~mW} / \mathrm{mm}^{2}$ (Figure 3D) and $\geq 5 \mathrm{~mW} / \mathrm{mm}^{2}$ (Figure $3 \mathrm{~F}$ ), respectively, effectively potentiated
UBD-evoked VMRs in $\operatorname{Tr} p v 1^{\mathrm{Cre}}$;Ai32 and Scn10a ${ }^{\mathrm{Cre}}$;Ai32 mice. VMR behavior was not observed in response to transurethral laser stimulation alone, but could be evoked in both groups via transabdominal, direct (without the use of a fiber optic) photostimulation of the bladder at $50 \mathrm{~mW} / \mathrm{mm}^{2}$ maximal intensity (data not shown). In the latter case, the onset of the VMR usually occurred within 2 s of laser stimulation as typically seen with distension, and generally continued for the duration of the stimulation, with occasional after-discharges.

To determine the capacity to which optogenetic activation of peripheral afferent terminals can drive micturition reflex activity, in vivo bladder contractile responses to light stimulation were measured in $\operatorname{Tr} p v 1^{\mathrm{Cre}} ; \mathrm{Ai} 32$ and $\mathrm{Scn} 10 a^{\mathrm{Cre}} ; \mathrm{Ai} 32$ mice. First, IVP during saline infusion was measured to assess normal bladder function in each mouse. Saline infusion elicited low amplitude ( $\triangle \mathrm{IVP}<7.5 \mathrm{mmHg}$ ) bladder contractile activity previously described as "non-voiding" contractions (Birder et al., 2002), that were followed by larger ( $\Delta$ IVP $\geq 7.5 \mathrm{mmHg}$ ), phasic contractions indicative of voiding (Cockayne et al., 2000). There were no differences between $\operatorname{Trp} v 1^{\mathrm{Cre}} ; \mathrm{Ai} 32(n=5)$ and Scn $10 a^{\mathrm{Cre}}$;Ai32 $(n=5)$ mice in baseline IVP $(2.83 \pm 0.76 \mathrm{mmHg}$ and $2.17 \pm 0.51 \mathrm{mmHg}$, respectively), nor were there differences in MT $(0.14 \pm 0.06 \mathrm{ml}$ and $0.13 \pm 0.05 \mathrm{ml}$, respectively) 


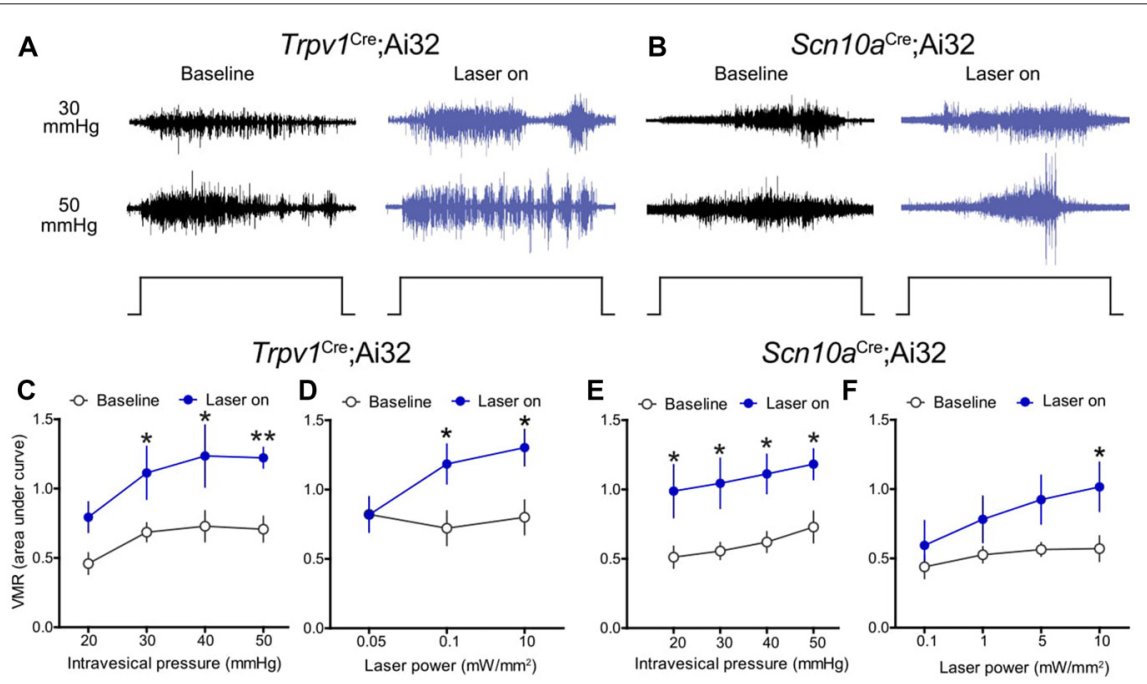

FIGURE 3 | Optical stimulation of ChR2+ bladder afferents potentiated bladder nociception. (A,B) Representative raw EMG traces from Trpv $1{ }^{\text {Cre }}$;Ai32 and $\mathrm{Scn} 10 \mathrm{a}^{\mathrm{Cre}}$;Ai32 mice during 30 and $50 \mathrm{mmHg}$ bladder distension before (baseline) and during (laser on) blue light illumination. (C) Transurethral fiber optic delivery of blue light to the bladder lumen (laser on) in $\operatorname{Trpv}{ }{ }^{\mathrm{Cre}}$;Ai32 mice significantly increased the evoked responses to bladder distension compared with pre-laser (baseline) responses $(* * P<0.01$, two-way ANOVA; $n=8$ mice). Significant potentiation occurred at noxious distension pressures $(30-50 \mathrm{mmHg}$, all $P$ values $<0.05)$. (D) Potentiation of the VMR was light intensity-dependent in Trpv $1{ }^{\text {Cre }}$;Ai32 mice $(* P<0.05$, two-way ANOVA; $n=6$ mice). (E) Optical stimulation of ChR2+ bladder afferents (laser on) significantly increased the evoked response to bladder distension compared with pre-laser (baseline) responses in Scn10aCre ;Ai32 mice $\left({ }^{*} P<0.05\right.$, two-way ANOVA; $n=8$ mice). Distension-evoked responses were potentiated at both noxious $\left(30-50 \mathrm{mmHg},{ }^{*} P\right.$ values $\left.<0.05\right)$ and non-noxious $\left(20 \mathrm{mmHg},{ }^{*} P<0.05\right)$ pressures. (F) As in Trpv $1{ }^{\mathrm{Cre}}$;Ai32 mice, potentiation of the VMR was light intensity-dependent in Scn10a ${ }^{\mathrm{Cre}}$;Ai32 mice $\left(^{*} P<0.05\right.$, two-way ANOVA; $n=6$ mice).
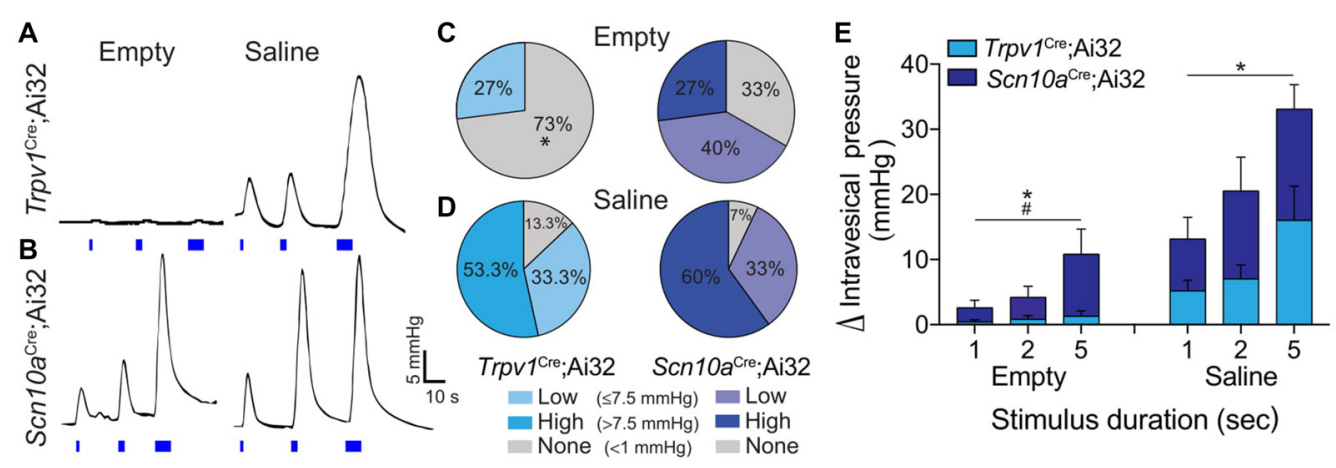

Stimulus duration (sec)

FIGURE 4 | Optogenetic stimulation of ChR2+ bladder afferents revealed population-specific effects on bladder contractile activity. (A,B) Representative traces of $\Delta I V P$ in response to 1,2 and $5 \mathrm{~s}$ light stimulation (blue bars) of peripheral bladder afferent terminals in Trpv 1 Cre ;Ai32 and Scn10aCre;Ai32 mice when bladders were drained prior to light stimulation (empty) and following saline distension to $80 \%$ of micturition threshold (MT; saline). (C,D) Graphs show the percentage of stimulation trials in Trpv $1^{\text {Cre }}$; Ai32 and Scn10aCre; Ai32 mice in which low amplitude ( $>1.0$ but $<7.5 \mathrm{mmHg}$ ) or high amplitude ( $\geq 7.5 \mathrm{mmHg}$ ) bladder contractions, or no change in intravesical pressure (IVP), were recorded in response to light stimulation during empty and saline conditions $\left({ }^{*} P<0.05\right.$, Chi-square; $n=5$ per group). (E) $\Delta \mathrm{IVP}$ when the bladder was drained prior to light stimulation (empty) was dependent on stimulus duration $\left({ }^{*} P<0.05\right)$ but not mouse line $(P=0.08)$, with a significant interaction ( $\left.{ }^{\#} P<0.05\right)$. There was also an effect of stimulus duration $\left({ }^{*} P<0.05\right)$ when the bladder was pre-distended (saline), but no effect of mouse line $(P>0.05)$ and no interaction $(P>0.05)$. Two way ANOVAs with repeated measures, $n=5$ per group.

or PT $(14.62 \pm 2.26 \mathrm{mmHg}$ and $17.53 \pm 3.42 \mathrm{mmHg}$, respectively). In the same mice, the effects of ChR2-mediated depolarization of peripheral afferent terminals on bladder contractile activity was examined. In both mouse lines, the amplitude of light-evoked bladder contractions was durationdependent, such that longer light pulses elicited a larger $\triangle I V P$ (Figures 4A,B,E); however, differential effects were observed between $\operatorname{Tr} p v 1^{\mathrm{Cre}} ; \mathrm{Ai} 32$ and $\mathrm{Scn} 10 a^{\mathrm{Cre}} ; \mathrm{Ai} 32$ mice. Light stimulation was more likely to produce bladder contractions in Scn $10 a^{\mathrm{Cre}}$;Ai32 than in $\operatorname{Tr} p v 1^{\mathrm{Cre}}$;Ai32 mice when the bladder was empty $\left(\chi_{(1)}^{2}=4.821, P<0.05\right)$. Stimulation of the empty bladder elicited low amplitude ( $>1.0$ but $<7.5 \mathrm{mmHg}$ ), "non-voiding" contractions in $27 \%(4 / 15)$ of the trials in $\operatorname{Trp} v 1^{\mathrm{Cre}}$;Ai32 mice and $40 \%(6 / 15)$ of the trials in Scn10a ${ }^{\mathrm{Cre}}$;Ai32 mice (Figure 4C). 
Micturition contractions $(>7.5 \mathrm{mmHg}$ ) were observed in $0 \%$ $(0 / 15)$ of the empty trials in $\operatorname{Trpv1}{ }^{\mathrm{Cre}}$;Ai32 mice and $27 \%$ $(4 / 15)$ in Scn10a ${ }^{\mathrm{Cre}}$;Ai32 mice (Figure 4C). Because physiological micturition contractions occur as a result of bladder fillinginduced activity of LT, mechanosensitive afferents, a second set of light stimulation trials was performed after saline was infused into the bladder to reach $80 \%$ of the MT, as initially determined for each mouse. In this condition, there was no difference in the likelihood of light-evoked contractions, which

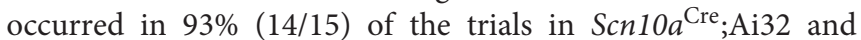
$87 \%(13 / 15)$ of the trials in Trpv1 ${ }^{\mathrm{Cre}}$;Ai32 mice $\left(\chi_{(1)}^{2}=2.143\right.$, $P>0.05)$. The majority of contractions were $\geq 7.5 \mathrm{mmHg}$ in both groups (Figure $4 \mathrm{D}$ ). When two-way repeated measures ANOVAs were used to analyze the effects of stimulus duration on $\triangle \mathrm{IVP}$ (Figure 4E), there was a significant main effect of stimulus duration regardless of bladder filling, which did not depend on the fiber types being stimulated. There was, however, a significant interaction between these two groups and stimulus duration when the bladder was empty, such that the $\triangle$ IVP was greater with longer stimulation in $\mathrm{Scn}_{10 a^{\mathrm{Cre}}}$;Ai32 mice $\left(F_{(2,16)}=3.779\right.$, $P<0.05)$.

\section{Differential Spinal Synaptic Communication between Trpv1 ${ }^{\mathrm{Cre}}$;Ai32 and Scn10a ${ }^{\mathrm{Cre}}$;Ai32 Mice}

To further examine potential divergent roles of lineage Trpv1+ and Scn10a+ afferents, we assessed differences in spinal cord synaptic connectivity in $\mathrm{Trpv}_{1}{ }^{\mathrm{Cre}} ; \mathrm{Ai} 32$ and $\mathrm{Scn} 10 a^{\mathrm{Cre}} ; \mathrm{Ai} 32$ mice. We performed whole-cell patch-clamp recordings from acute LS spinal cord slices (Figures 5A,B) and used brief $(1 \mathrm{~ms})$ pulses of $470 \mathrm{~nm}$ light to stimulate ChR2-expressing primary afferent central terminals (Figure 5B). Recordings from neurons in laminae I-II, which exhibited similar patterns of eYFP expression in both mouse lines (Figures 1I,J), revealed no difference in amplitude of excitatory postsynaptic currents (EPSCs; Unpaired $t$-test; $n=5-9$ cells; Figures 5D,E). We also calculated the charge transfer to quantify polysynaptic input onto neurons, and found no difference between these transgenic lines in laminae I/II (Figure 5C). However, in recordings from neurons in deeper laminae (III/IV) that are more densely innervated by ChR2+ afferents in $\mathrm{Scn} 10 a^{\mathrm{Cre}}$;Ai32 mice, we found enhanced EPSC amplitudes and significantly increased charge transfer compared to deeper laminae recordings in Trpv1 ${ }^{\text {Cre }}$;Ai32 mice (Unpaired $t$-test, $P<0.05 ; n=6-7$ cells; Figures $5 \mathrm{~F}-\mathbf{H}$ ).

\section{DISCUSSION}

In the current study, we demonstrate successful application of optogenetics to in vivo modulation of bladder sensation as it relates to both nociception and voiding. A transgenic strategy was used to express ChR2 in select populations of afferents via $\mathrm{Trpv}^{\mathrm{Cre}}$ (Cavanaugh et al., 2011b) and SNS ${ }^{\mathrm{Cre}}$ (i.e., Scn10a ${ }^{\mathrm{Cre}}$; Agarwal et al., 2004). Photostimulation of $\mathrm{ChR} 2+$ peripheral bladder afferent terminals differentially modulated bladder sensory pathways in Trpv1 ${ }^{\mathrm{Cre}}$;Ai32 and $\mathrm{Scn} 10 a^{\mathrm{Cre}}$;Ai32 mice. Light stimulation significantly enhanced nociceptive reflex behavior (VMR) evoked by a range of noxious distension pressures (30-50 $\mathrm{mmHg}$ ) in both ChR2-expressing mouse lines. Further, stimulation in $\mathrm{Scn}_{10 a^{\mathrm{Cre}}}$;Ai32, but not $\operatorname{Trpv}^{\mathrm{Cre}}{ }^{\mathrm{C}} \mathrm{Ai} 32$, mice potentiated the VMR to non-noxious bladder distension, suggesting that alterations in the threshold or functional activity of this population may be important for sensations of discomfort or urgency at physiologic IVPs.

In voiding reflex studies, contractile activity of the bladder was elicited by peripheral afferent terminal activation that depended on the fiber types targeted. Afferent depolarization in Trpv1 ${ }^{\mathrm{Cre}}$;Ai32 mice elicited little or no contractile activity unless the bladder was partially filled with saline. This prerequisite engagement of low-threshold mechanosensitive afferents is in agreement with the longstanding hypothesis that C-fiber afferents primarily act to modulate, rather than initiate, micturition. In contrast, photostimulation of bladder afferents in Scn $10 a^{\mathrm{Cre}}$;Ai32 mice elicited both small $(<7.5 \mathrm{mmHg})$ and large $(\geq 7.5 \mathrm{mmHg}$ ) amplitude contractile activity whether the bladder was empty or partially filled. This finding is consistent with evidence that bladder afferents terminating in deeper laminae directly engage micturition pathways. In $\mathrm{Scn} 10 a^{\mathrm{Cre}} ; \mathrm{Ai} 32$ mice, eYFP+ fibers projected densely throughout laminae I-V, into lamina $\mathrm{X}$, and throughout the dorsal columns. However, it is worth noting that $\mathrm{eYFP}+$ fibers did not appear to terminate on parasympathetic preganglionic neurons in the SPN region of the spinal cord; rather, they terminate on interneurons that synapse on these preganglionic neurons or ascend to engage the bulbo-spinal micturition pathway. An additional possibility is that connectivity between central $\mathrm{ChR} 2+$ afferent projections and the lateral spinal nucleus (LSN) is enhanced in $\mathrm{Scn} 10 a^{\mathrm{Cre}}$;Ai32 compared to $\operatorname{Trpv}^{\mathrm{Cre}}$;Ai32 mice. The LSN has a demonstrated role in polysynaptic transmission and/or modulation of afferent sensory information with preference for deep tissues, and in fact receives sparse, but direct, visceral afferent input (Sikandar et al., 2017). In turn, the LSN projects to and receives projections from a large number of supraspinal sites important for sensory processing and modulation of both pain and micturition (e.g., periaqueductal gray, thalamus, hypothalamus, amygdala; Burstein et al., 1987; Harmann et al., 1988; Battaglia and Rustioni, 1992; Burstein and Potrebic, 1993). Thus, although the LSN may contribute to enhancement of distension-evoked nociceptive responses by light stimulation in both $\mathrm{Scn} 10 a^{\mathrm{Cre}} ; \mathrm{Ai} 32$ and $\operatorname{Trpv1}{ }^{\mathrm{Cre}} ; \mathrm{Ai} 32$ mice, it may also contribute to differential contractile activity depending on the identity of the stimulated fibers through additional mechanisms discussed below.

There are several additional potential explanations for differences in photostimulation effects, including the fiber types of $\mathrm{ChR} 2+$ terminals (myelinated vs. unmyelinated), the response threshold (LT vs. HT) of ChR2+ bladder afferents, and/or the total number of bladder-innervating $\mathrm{ChR} 2+$ neurons in Trpv1 ${ }^{\mathrm{Cre}}$;Ai32 and $\mathrm{Scn} 10 a^{\mathrm{Cre}}$;Ai32 mouse lines. In contrast to somatic nerves in which CT $\beta$ is transported by neurons with myelinated axons and conduction velocities in the A-fiber range (Robertson and Grant, 1989; LaMotte et al., 1991), CT $\beta$ labels a combination of myelinated and unmyelinated visceral afferent neurons (Wang et al., 1998; Fasanella et al., 2008; 

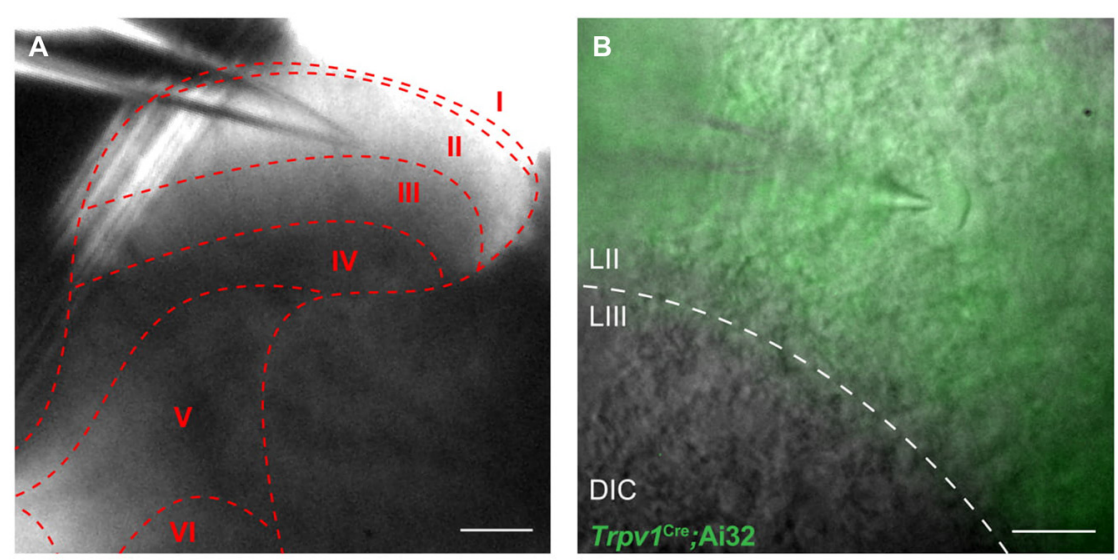

\section{Lamina II}
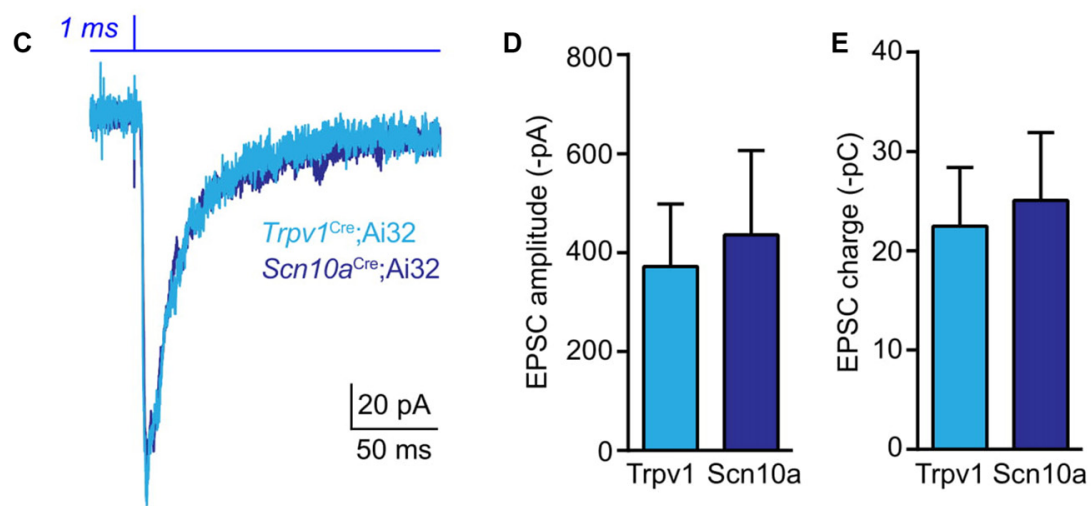

\section{Laminae III/IV}
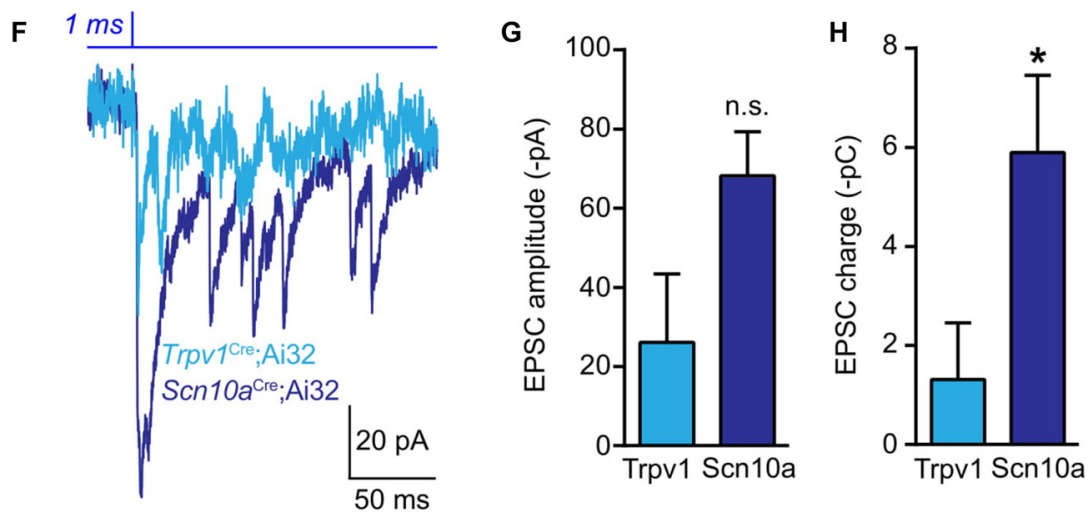

FIGURE 5 | Spinal functional connectivity in Trpv1 ${ }^{\mathrm{Cre}}$;Ai32 and Scn10aCre;Ai32 mice. (A,B) Representative images showing location of recording electrode in spinal cord slice from Trpv1 ${ }^{\mathrm{Cre}}$;Ai32 mice. (C) Representative traces recorded during optogenetic activation of excitatory synaptic transmission from ChR2+ primary afferents in voltage clamp recordings from laminae I-II in Trpv1 ${ }^{\mathrm{Cre}}$;Ai32 and Scn10a ${ }^{\mathrm{Cre}}$;Ai32 mice. (D,E) In Trpv1 ${ }^{\mathrm{Cre}}$;Ai32 and Scn10aCre;Ai32 mice, there was no significant difference in the amplitude of EPSCs or charge transfer $(P>0.05$, unpaired $t$-test; $n=9$ cells for Trpv 1 Cre $;$ Ai32 and $n=5$ cells for Scn10aCre;Ai32). (F) Representative traces of excitatory synaptic currents during voltage clamp recordings from laminae III/IV in Trpv1 Cre ;Ai32 and Scn10a Cre;Ai32 mice. (G) There was no significant difference between in the amplitude of excitatory currents. (H) In spinal laminae III/IV of Scn10aCre;Ai32 mice, a significant increase in charge transfer was observed compared to $\operatorname{Trpv} 1{ }^{\mathrm{Cre}}$;Ai32 mice $\left({ }^{*} P<0.05\right.$, unpaired $t$-test; $n=7$ cells for Trpv ${ }^{\mathrm{Cre}}$;Ai32 and $n=6$ cells for Scn10aCre ;Ai32).

Zhong et al., 2008). Thus, it is possible that $\operatorname{Scn} 10 a^{\mathrm{Cre}}$;Ai32 and $\operatorname{Trp} v 1^{\mathrm{Cre}}$;Ai32 mice express differing proportions of ChR2eYFP+ neurons with myelinated vs. unmyelinated fibers. Using immunohistochemical techniques, TRPV1 has been identified as a neurochemical marker preferentially expressed by unmyelinated visceral afferents in rat (De Schepper et al., 2008; Forrest et al., 2013) and in mouse (Fasanella et al., 2008; Zhong et al., 2008). In support of this, previous work on mouse colon afferents found that $87 \%$ were TRPV1-positive, all of which had conduction velocities in the range of $\mathrm{C}$-fiber 
afferents, and had high response thresholds to distension with low firing frequency that remained relatively constant across stimulus intensities (Malin et al., 2009). This is in contrast to neurochemical studies suggesting that targeting $\mathrm{Na}_{\mathrm{v}} 1.8^{+}$ neurons includes the majority of C-fibers, including peptidergic and non-peptidergic nociceptors, VGLUT3+ low-threshold mechanosensitive types, and in nearly one-third of NF200+, A-fiber afferents (Black et al., 1996, 2003; Shields et al., 2012). The majority of bladder afferent neurons in rat exhibit TTX-resistant $\mathrm{Na}^{+}$currents that contribute to high electrical thresholds for action potential firing (Yoshimura et al., 1996). This population is significantly reduced by capsaicin treatment, suggesting that a significant proportion of these afferents express TRPV1 (Yoshimura et al., 1996). Experimental reduction in the expression of $\mathrm{Na}_{\mathrm{v}} 1.8$ via antisense oligodeoxynucleotide treatment reduces TTX-resistant $\mathrm{Na}^{+}$conductance in bladder afferent neurons, indicating that the aforementioned population overlap with $\mathrm{Na}_{\mathrm{v}} 1.8$-expressing neurons (Yoshimura et al., 2001). Thus, one might reasonably extrapolate that ChR2expressing bladder afferents in Trpv1 ${ }^{\mathrm{Cre}} ; \mathrm{Ai} 32$ mice in the current study comprise the high threshold, TTX-resistant $\left(\mathrm{Na}_{\mathrm{v}} 1.8^{+}\right)$ population of C-fibers that do not normally respond to physiological bladder filling. This notion is supported by the prerequisite engagement of low threshold mechanosensitive afferents by sub-threshold saline infusion to generate large amplitude bladder contractions in the cystometric studies reported here. In turn, the higher percentage (by 20\%-30\%) of ChR2-expressing bladder afferents in Scn10a ${ }^{\mathrm{Cre}}$;Ai32 mice (relative to the Trpv1 ${ }^{\mathrm{Cre}}$; Ai32 mice) likely represents the lowthreshold population of afferents that normally respond to bladder filling.

Previous characterization of Trpv1 ${ }^{\mathrm{Cre}}$ mice demonstrated that this transgenic line targets both peptidergic and non-peptidergic C-fibers (Cavanaugh et al., 2011a). This is confirmed by eYFP+ central projections in Trpv1 ${ }^{\mathrm{Cre}}$;Ai32 fibers that were largely restricted to the superficial DH, i.e., laminae I-II, where the majority of peptidergic and non-peptidergic C-fiber afferents respectively terminate. Thus, the appearance of eYFP+ projections to laminae III-V and heavier projections to lamina $\mathrm{X}$ in $\mathrm{Scn} 10 a^{\mathrm{Cre}}$;Ai32 mice is likely due to the expression of ChR2-eYFP in myelinated A-fiber afferents in addition to C-fiber afferents (Shields et al., 2012). In spinal cord slice electrophysiology experiments, we observed elevated functional connectivity in $\mathrm{Scn} 10 a^{\mathrm{Cre}}$; $\mathrm{Ai} 32$ mice between $\mathrm{ChR} 2+$ afferents and second order neurons in deeper (III-IV), but not superficial (I-II), laminae of the DH compared to $\mathrm{ChR} 2+$ fibers in Trpv1 ${ }^{\mathrm{Cre}}$;Ai32 mice. Although the vast majority of bladder afferent input to the DH is to laminae I, V-VII and X, sparse inputs to laminae III-IV occasionally have been shown by pseudorabies virus labeling or c-Fos expression (e.g., Vizzard et al., 1996; Vizzard, 2000). Speculatively, it is possible that A $\delta$ fibers labeled by ChR2-eYFP in $\mathrm{Scn} 10 a^{\mathrm{Cre}}$; $\mathrm{Ai} 32$ mice contributes to the enhanced synaptic communication between incoming afferents and the neurons located in deeper laminae, resulting in differential processing of visceral information conveyed by sensory neurons innervating the bladder. That excitation of myelinated, A 8 -fiber afferents in $\mathrm{Scn} 10 a^{\mathrm{Cre}}$;Ai32 mice may be responsible for driving the voiding contractions is also in accordance with previous rat studies that have utilized chemical desensitization of capsaicin-sensitive bladder afferents (i.e., TRPV1+ C-fibers) to show that $\mathrm{A} \delta$-fiber afferents mediate normal micturition (Cheng et al., 1993).

Alternatively, increased visceromotor and voiding reflex behavior in $\mathrm{Scn} 10 a^{\mathrm{Cre}}$;Ai32 mice could be due to stimulation of a greater overall number of ChR2+ bladder afferents than in $\operatorname{Trpv1}{ }^{\mathrm{Cre}}$;Ai32 mice. Compared to $62 \%$ in $\operatorname{Trpv}^{\mathrm{Cre}}$;Ai32 mice, $82.2 \%$ of retrogradely labeled LS DRG neurons expressed ChR2-eYFP in Scn10a Cre;Ai32 mice. Previous reports (La et al., 2011; DeBerry et al., 2014) of Trpv1 mRNA and functional protein expression in $\sim 60 \%$ of LS bladder afferents are in accordance with the present results. The observed proportion of eYFP+ bladder afferents in $\mathrm{Scn}_{10 a^{\mathrm{Cre}}}$;Ai32 mice was slightly higher than previous reports of $\mathrm{Na}_{\mathrm{v}} 1.8$ expression in $75 \%$ of mouse DRG neurons (Shields et al., 2012), and higher than the $70 \%-74 \%$ of bladder afferents in rat that exhibit TTX-resistant, $\mathrm{Na}_{\mathrm{v}}$ 1.8-mediated sodium currents (Yoshimura et al., 1996, 2006; Masuda et al., 2006). It is important to note that in all of these studies and in the present study, retrograde labeling of afferent somata was achieved by microinjection of CT $\beta$ into the bladder parenchyma, which labels a distinct anatomical subset of non-urothelial, bladder-innervating primary afferents (Kanda et al., 2016; Clodfelder-Miller et al., 2017). Whether there are differences in the proportion of peri-urothelial afferents in $\operatorname{Trpv1}{ }^{\mathrm{Cre}} ; \mathrm{Ai} 32$ vs. Scn10a ${ }^{\mathrm{Cre}} ; \mathrm{Ai} 32$ mice and whether peri-urothelial afferents provide sensory input that is unique from that of the non-urothelial afferents studied here remains to be determined.

Expression of ChR2 in the CNS has been used to study a number of behaviors, including those related to anxiety, learning, and depression (Huber et al., 2008; Covington et al., 2010; Tye et al., 2011). Recently, optogenetic modulation of bladder smooth muscle was shown to elicit voiding in vivo (Park et al., 2017), and our group demonstrated that inhibition of sensory afferent activity via archaerhodopsin, a lightactivated proton pump, attenuates pain-related behavior in the context of bladder inflammation (Samineni et al., 2017a). The present study is an important addition that demonstrates for the first time the effects of direct, selective neuronal activation of distinct bladder afferents on behavioral correlates of bladder sensation and function. Selective optogenetic activation of primary afferent activity differentially modulated transmission of nociceptive sensory information and autonomic reflexes initiated by primary sensory afferents. This optogenetic approach may also prove useful for understanding pain processing in other visceral systems given that sensory afferents, including those that innervate the parenchyma and vasculature of a given organ, are important for both pain and homeostasis.

\section{ETHICS STATEMENT}

All experiments were conducted in accordance with the National Institute of Health guidelines and with approval from the Institutional Animal Care and Use Committees of University 
of Alabama at Birmingham, University of Pittsburgh, and Washington University School of Medicine.

\section{AUTHOR CONTRIBUTIONS}

JJD and VKS collected the data. JJD, VKS, BMD and RWG designed the experiments, analyzed the data and wrote the manuscript. BAC performed electrophysiological experiments. SKV and CJS performed breeding and anatomical analyses. KMA provided resources.

\section{REFERENCES}

Agarwal, N., Offermanns, S., and Kuner, R. (2004). Conditional gene deletion in primary nociceptive neurons of trigeminal ganglia and dorsal root ganglia. Genesis 38, 122-129. doi: 10.1002/gene.20010

Battaglia, G., and Rustioni, A. (1992). Substance P innervation of the rat and cat thalamus. J. Comp. Neurol. 315, 473-486. doi: 10.1002/cne.903150409

Baumbauer, K. M., DeBerry, J. J., Adelman, P. C., Miller, R. H., Hachisuka, J., Lee, K. H., et al. (2015). Keratinocytes can modulate and directly initiate nociceptive responses. Elife 4:e09674. doi: 10.7554/eLife.09674

Birder, L. A., and de Groat, W. C. (1993). Induction of c-fos expression in spinal neurons by nociceptive and nonnociceptive stimulation of LUT. Am. J. Physiol. 265, R326-R333. doi: 10.1152/ajpregu.1993.265.2.r326

Birder, L. A., Nakamura, Y., Kiss, S., Nealen, M. L., Barrick, S., Kanai, A. J., et al. (2002). Altered urinary bladder function in mice lacking the vanilloid receptor TRPV1. Nat. Neurosci. 5, 856-860. doi: 10.1038/nn902

Black, J. A., Cummins, T. R., Yoshimura, N., de Groat, W. C., and Waxman, S. G. (2003). Tetrodotoxin-resistant sodium channels $\mathrm{Na}_{\mathrm{v}} 1.8 / \mathrm{SNS}$ and $\mathrm{Na}_{\mathrm{v}} 1.9 / \mathrm{NaN}$ in afferent neurons innervating urinary bladder in control and spinal cord injured rats. Brain Res. 963, 132-138. doi: 10.1016/s0006-8993(02)03957-4

Black, J. A., Dib-Hajj, S., McNabola, K., Jeste, S., Rizzo, M. A., Kocsis, J. D., et al. (1996). Spinal sensory neurons express multiple sodium channel $\alpha$-subunit mRNAs. Mol. Brain Res. 43, 117-131. doi: 10.1016/s0169-328x(96)00163-5

Boada, M. D., Martin, T. J., Peters, C. M., Hayashida, K., Harris, M. H., Houle, T. T., et al. (2014). Fast-conducting mechanoreceptors contribute to withdrawal behavior in normal and nerve injured rats. Pain 155, 2646-2655. doi: 10.1016/j.pain.2014.09.030

Boyden, E. S., Zhang, F., Bamberg, E., Nagel, G., and Deisseroth, K. (2005). Millisecond-timescale, genetically targeted optical control of neural activity. Nat. Neurosci. 8, 1263-1268. doi: 10.1038/nn1525

Burstein, R., Cliffer, K. D., and Giesler, G. J. Jr. (1987). Direct somatosensory projections from the spinal cord to the hypothalamus and telencephalon. J. Neurosci. 7, 4159-4164.

Burstein, R., and Potrebic, S. (1993). Retrograde labeling of neurons in the spinal cord that project directly to the amygdala or the orbital cortex in the rat. J. Comp. Neurol. 335, 469-485. doi: 10.1002/cne.903350402

Castroman, P., and Ness, T. J. (2001). Vigor of visceromotor responses to urinary bladder distension in rats increases with repeated trials and stimulus intensity. Neurosci. Lett. 306, 97-100. doi: 10.1016/s0304-3940(01)01886-9

Cavanaugh, D. J., Chesler, A. T., Báaz, J. M., Shah, N. M., Julius, D., and Basbaum, A. I. (2011a). Restriction of transient receptor potential vanilloid-1 to the peptidergic subset of primary afferent neurons follows its developmental downregulation in nonpeptidergic neurons. J. Neurosci. 31, 10119-10127. doi: 10.1523/JNEUROSCI.1299-11.2011

Cavanaugh, D. J., Chesler, A. T., Jackson, A. C., Sigal, Y. M., Yamanaka, H., Grant, R., et al. (2011b). Trpv1 reporter mice reveal highly restricted brain distribution and functional expression in arteriolar smooth muscle cells. J. Neurosci. 31, 5067-5077. doi: 10.1523/JNEUROSCI.6451-10.2011

Cavanaugh, D. J., Lee, H., Lo, L., Shields, S. D., Zylka, M. J., Basbaum, A. I., et al. (2009). Distinct subsets of unmyelinated primary sensory fibers mediate behavioral responses to noxious thermal and mechanical stimuli. Proc. Natl. Acad. Sci. U S A 106, 9075-9080. doi: 10.1073/pnas. 0901507106

\section{ACKNOWLEDGMENTS}

This work was funded by the National Institutes of Health (NIH) Director's Transformative Research Award (TR01 NS081707), NIH SPARC award (NIBIB U18EB021793), and R01NS42595 to RWG, Urology Care Foundation Research Scholars Program and Kailash Kedia Research Scholar award to VKS, NIH SPARC award (U18 EB021877), R01NS050758, and R01DK093525 to BMD, and NIH K01DK101681 to JJD. We thank Janet M. Sinn-Hanlon for help with illustrations.

Charrua, A., Reguenga, C., Cordeiro, J. M., Correiade-Sá, P., Paule, C., Nagy, I., et al. (2009). Functional transient receptor potential vanilloid 1 is expressed in human urothelial cells. J. Urol. 182, 2944-2950. doi: 10.1016/j.juro.2009.08.022

Cheng, C. L., Ma, C. P., and de Groat, W. C. (1993). Effects of capsaicin on micturition and associated reflexes in rats. Am. J. Physiol. 265, R132-R138. doi: 10.1152/ajpregu.1993.265.1.r132

Cheng, C. L., Ma, C. P., and de Groat, W. C. (1995). Effect of capsaicin on micturition and associated reflexes in chronic spinal rats. Brain Res. 678, 40-48. doi: 10.1016/0006-8993(95)00212-9

Chiu, I. M., Barrett, L. B., Williams, E., Strochlic, D. E., Lee, S., Weyer, A. D., et al. (2014). Transcriptional profiling at whole population and single cell levels reveals somatosensory neuron molecular diversity. Elife 3:e04660. doi: 10.7554/eLife.04660

Christianson, J. A., Traub, R. J., and Davis, B. M. (2006). Differences in spinal distribution and neurochemical phenotype of colonic afferents in mouse and rat. J. Comp. Neurol. 494, 246-259. doi: 10.1002/cne.20816

Clodfelder-Miller, B. J., Kanda, H., Gu, J. G., Creighton, J. R., Ness, T. J., and DeBerry, J. J. (2017). Urothelial bladder afferent neurons in the rat are anatomically and neurochemically distinct from non-urothelial afferents. Brain Res. doi: 10.1016/j.brainres.2017.12.023 [Epub ahead of print].

Cockayne, D. A., Hamilton, S. G., Zhu, Q. M., Dunn, P. M., Zhong, Y., Novakovic, S., et al. (2000). Urinary bladder hyporeflexia and reduced pain-related behaviour in P2X3-deficient mice. Nature 407, 1011-1015. doi: 10.1038/35039519

Copits, B. A., Pullen, M. Y., and Gereau, R. W. (2016). Spotlight on pain: optogenetic approaches for interrogating somatosensory circuits. Pain 157, 2424-2433. doi: 10.1097/j.pain.0000000000000620

Covington, H. E. III., Lobo, M. K., Maze, I., Vialou, V., Hyman, J. M., Zaman, S., et al. (2010). Antidepressant effect of optogenetic stimulation of the medial prefrontal cortex. J. Neurosci. 30, 16082-16090. doi: 10.1523/JNEUROSCI. 1731-10.2010

Crock, L. W., Stemler, K. M., Song, D. G., Abbosh, P., Vogt, S. K., Qiu, C. S. et al. (2012). Metabotropic glutamate receptor 5 (mGluR5) regulates bladder nociception. Mol. Pain 8:20. doi: 10.1186/1744-8069-8-20

Daly, D., Rong, W., Chess-Williams, R., Chapple, C., and Grundy, D. (2007). Bladder afferent sensitivity in wild-type and TRPV1 knockout mice. J. Physiol. 583, 663-674. doi: 10.1113/jphysiol.2007.139147

Daou, I., Tuttle, A. H., Longo, G., Wieskopf, J. S., Bonin, R. P., Ase, A. R., et al. (2013). Remote optogenetic activation and sensitization of pain pathways in freely moving mice. J. Neurosci. 33, 18631-18640. doi: 10.1523/JNEUROSCI. 2424-13.2013

DeBerry, J. J., Saloman, J. L., Dragoo, B. K., Albers, K. M., and Davis, B. M. (2015). Artemin immunotherapy is effective in preventing and reversing cystitisinduced bladder hyperalgesia via TRPA1 regulation. J. Pain 16, 628-636. doi: 10.1016/j.jpain.2015.03.014

DeBerry, J. J., Schwartz, E. S., and Davis, B. M. (2014). TRPA1 mediates bladder hyperalgesia in a mouse model of cystitis. Pain 155, 1280-1287. doi: 10.1016/ j.pain.2014.03.023

De Schepper, H. U., De Winter, B. Y., Van Nassauw, L., Timmermans, J. P., Herman, A. G., Pelckmans, P. A., et al. (2008). TRPV1 receptors on unmyelinated C-fibres mediate colitis-induced sensitization of pelvic afferent nerve fibres in rats. J. Physiol. 586, 5247-5258. doi: 10.1113/jphysiol.2008. 159731 
Espinosa-Medina, I., Saha, O., Boismoreau, F., and Brunet, J. F. (2017). The "sacral parasympathetic": ontogeny and anatomy of a myth. Clin. Auton. Res. doi: 10.1007/s10286-017-0478-7 [Epub ahead of print].

Espinosa-Medina, I., Saha, O., Boismoreau, F., Chettouh, Z., Rossi, F., Richardson, W. D., et al. (2016). The sacral autonomic outflow is sympathetic. Science 354, 893-897. doi: 10.1126/science.aah5454

Fasanella, K. E., Christianson, J. A., Chanthaphavong, R. S., and Davis, B. M. (2008). Distribution and neurochemical identification of pancreatic afferents in the mouse. J. Comp. Neurol. 509, 42-52. doi: 10.1002/cne. 21736

Forrest, S. L., Osborne, P. B., and Keast, J. R. (2013). Characterization of bladder sensory neurons in the context of myelination, receptors for pain modulators, and acute responses to bladder inflammation. Front. Neurosci. 7:206. doi: 10.3389/fnins.2013.00206

Harmann, P. A., Carlton, S. M., and Willis, W. D. (1988). Collaterals of spinothalamic tract cells to the periaqueductal gray: a fluorescent doublelabeling study in the rat. Brain Res. 441, 87-97. doi: 10.1016/00068993(88)91386-8

Huber, D., Petreanu, L., Ghitani, N., Ranade, S., Hromádka, T., Mainen, Z., et al. (2008). Sparse optical microstimulation in barrel cortex drives learned behaviour in freely moving mice. Nature 451, 61-64. doi: 10.1038/ nature 06445

Iyer, S. M., Montgomery, K. L., Towne, C., Lee, S. Y., Ramakrishnan, C., Deisseroth, K., et al. (2014). Virally mediated optogenetic excitation and inhibition of pain in freely moving nontransgenic mice. Nat. Biotechnol. 32, 274-278. doi: 10.1038/nbt.2834

Ji, Z. G., Ito, S., Honjoh, T., Ohta, H., Ishizuka, T., Fukazawa, Y., et al. (2012). Light-evoked somatosensory perception of transgenic rats that express channelrhodopsin-2 in dorsal root ganglion cells. PLoS One 7:e32699. doi: 10.1371/journal.pone.0032699

Kanda, H., Clodfelder-Miller, B. J., Gu, J. G., Ness, T. J., and DeBerry, J. J. (2016). Electrophysiological properties of lumbosacral primary afferent neurons innervating urothelial and non-urothelial layers of mouse urinary bladder. Brain Res. 1648, 81-89. doi: 10.1016/j.brainres. 2016.06.042

La, J. H., Schwartz, E. S., and Gebhart, G. F. (2011). Differences in the expression of transient receptor potential channel V1, transient receptor potential channel $\mathrm{A} 1$ and mechanosensitive two pore-domain $\mathrm{K}^{+}$channels between the lumbar splanchnic and pelvic nerve innervations of mouse urinary bladder and colon. Neuroscience 186, 179-187. doi: 10.1016/j.neuroscience. 2011.04.049

Laird, J. M., Souslova, V., Wood, J. N., and Cervero, F. (2002). Deficits in visceral pain and referred hyperalgesia in $\mathrm{Na}_{\mathrm{v}} 1.8$ (SNS/PN3)-null mice. J. Neurosci. 22, 8352-8356.

LaMotte, C. C., Kapadia, S. E., and Shapiro, C. M. (1991). Central projections of the sciatic, saphenous, median, and ulnar nerves of the rat demonstrated by transganglionic transport of choleragenoid-HRP (B-HRP) and wheat germ agglutinin-HRP (WGA-HRP). J. Comp. Neurol. 311, 546-562. doi: 10.1002/cne. 903110409

Leffler, A., Monter, B., and Koltzenburg, M. (2006). The role of the capsaicin receptor TRPV1 and acid-sensing ion channels (ASICS) in proton sensitivity of subpopulations of primary nociceptive neurons in rats and mice. Neuroscience 139, 699-709. doi: 10.1016/j.neuroscience.2005.12.020

Liu, Y., Abdel Samad, O., Zhang, L., Duan, B., Tong, Q. C., Lopes, C., et al. (2010). VGLUT2-dependent glutamate release from nociceptors is required to sense pain and suppress itch. Neuron 68, 543-556. doi: 10.1016/j.neuron. 2010.09.008

Madisen, L., Mao, T., Koch, H., Zhuo, J. M., Berenyi, A., Fujisawa, S., et al. (2012). A toolbox of Cre-dependent optogenetic transgenic mice for lightinduced activation and silencing. Nat. Neurosci. 15, 793-802. doi: 10.1038/ nn. 3078

Malin, S. A., Christianson, J. A., Bielefeldt, K., and Davis, B. M. (2009). TPRV1 expression defines functionally distinct pelvic colon afferents. J. Neurosci. 29, 743-752. doi: 10.1523/JNEUROSCI.3791-08.2009

Mallory, B., Steers, W. D., and De Groat, W. C. (1989). Electrophysiological study of micturition reflexes in rats. Am. J. Physiol. 257, R410-R421. doi: 10.1152/ajpregu.1989.257.2.r410

Masuda, N., Hayashi, Y., Matsuyoshi, H., Chancellor, M. B., de Groat, W. C., and Yoshimura, N. (2006). Characterization of hyperpolarization-activated current (Ih) in dorsal root ganglion neurons innervating rat urinary bladder. Brain Res. 1096, 40-52. doi: 10.1016/j.brainres.2006 04.085

Michael, G. J., and Priestley, J. V. (1999). Differential expression of the mRNA for the vanilloid receptor subtype 1 in cells of the adult rat dorsal root and nodose ganglia and its downregulation by axotomy. J. Neurosci. 19, 1844-1854.

Mishra, S. K., Tisel, S. M., Orestes, P., Bhangoo, S. K., and Hoon, M. A. (2011). TRPV1-lineage neurons are required for thermal sensation. EMBO J. 30, 582-593. doi: 10.1038/emboj.2010.325

Montgomery, K. L., Yeh, A. J., Ho, J. S., Tsao, V., Mohan Iyer, S., Grosenick, L., et al. (2015). Wirelessly powered, fully internal optogenetics for brain, spinal and peripheral circuits in mice. Nat. Methods 12, 969-974. doi: 10.1038/nmeth. 3536

Nadelhaft, I., Vera, P. L., Card, J. P., and Miselis, R. R. (1992). Central nervous system neurons labelled following the injection of pseudorabies virus into the rat urinary bladder. Neurosci. Lett. 143, 271-274. doi: 10.1016/03043940(92)90281-b

Ness, T. J., Lewis-Sides, A., and Castroman, P. (2001). Characterization of pressor and visceromotor reflex responses to bladder distention in rats: sources of variability and effect of analgesics. J. Urol. 165, 968-974. doi: 10.1097/00005392-200103000-00071

Ness, T. J., Randich, A., and Gebhart, G. F. (1991). Further behavioral evidence that colorectal distension is a 'noxious' visceral stimulus in rats. Neurosci. Lett. 131, 113-116. doi: 10.1016/0304-3940(91)90349-x

Park, J. H., Hong, J. K., Jang, J. Y., An, J., Lee, K. S., Kang, T. M. et al. (2017). Optogenetic modulation of urinary bladder contraction for lower urinary tract dysfunction. Sci. Rep. 7:40872. doi: 10.1038/ srep40872

Park, S. I., Brenner, D. S., Shin, G., Morgan, C. D., Copits, B. A., Chung, H. U., et al. (2015). Soft, stretchable, fully implantable miniaturized optoelectronic systems for wireless optogenetics. Nat. Biotechnol. 33, 1280-1286. doi: 10.1038/nbt.3415

Robertson, B., and Grant, G. (1989). Immunocytochemical evidence for the localization of the GM1 ganglioside in carbonic anhydrase-containing and RT 97-immunoreactive rat primary sensory neurons. J. Neurocytol. 18, 77-86. doi: 10.1007/bf01188426

Samineni, V. K., Mickle, A. D., Yoon, J., Grajales-Reyes, J. G., Pullen, M. Y., Crawford, K. E., et al. (2017a). Optogenetic silencing of nociceptive primary afferents reduces evoked and ongoing bladder pain. Sci. Rep. 7:15865 doi: 10.1038/s41598-017-16129-3

Samineni, V. K., Yoon, J., Crawford, K. E., Jeong, Y. R., McKenzie, K. C., Shin, G., et al. (2017b). Fully implantable, battery-free wireless optoelectronic devices for spinal optogenetics. Pain 158, 2108-2116. doi: 10.1097/j.pain. 0000000000000968

Sengupta, J. N., and Gebhart, G. F. (1994a). Mechanosensitive properties of pelvic nerve afferent fibers innervating the urinary bladder of the rat. J. Neurophysiol. 72, 2420-2430. doi: 10.1152/jn.1994.72.5.2420

Sengupta, J. N., and Gebhart, G. F. (1994b). Characterization of mechanosensitive pelvic nerve afferent fibers innervating the colon of the rat. J. Neurophysiol. 71, 2046-2060. doi: 10.1152/jn.1994.71.6.2046

Shea, V. K., Cai, R., Crepps, B., Mason, J. L., and Perl, E. R. (2000). Sensory fibers of the pelvic nerve innervating the Rat's urinary bladder. J. Neurophysiol. 84 , 1924-1933. doi: 10.1152/jn.2000.84.4.1924

Shields, S. D., Ahn, H. S., Yang, Y., Han, C., Seal, R. P., Wood, J. N., et al. (2012). $\mathrm{Na}_{\mathrm{v}} 1.8$ expression is not restricted to nociceptors in mouse peripheral nervous system. Pain 153, 2017-2030. doi: 10.1016/j.pain.2012.04.022

Sikandar, S., West, S. J., McMahon, S. B., Bennett, D. L., and Dickenson, A. H. (2017). Sensory processing of deep tissue nociception in the rat spinal cord and thalamic ventrobasal complex. Physiol. Rep. 5:e13323. doi: 10.14814/phy2. 13323

Su, X., Sengupta, J. N., and Gebhart, G. F. (1997). Effects of opioids on mechanosensitive pelvic nerve afferent fibers innervating the urinary bladder of the rat. J. Neurophysiol. 77, 1566-1580. doi: 10.1152/jn.1997.77.3.1566

Ting, J. T., Daigle, T. L., Chen, Q., and Feng, G. (2014). Acute brain slice methods for adult and aging animals: application of targeted patch clamp analysis and optogenetics. Methods Mol. Biol. 1183, 221-242. doi: 10.1007/978-1-49391096-0_14

Tye, K. M., Prakash, R., Kim, S. Y., Fenno, L. E., Grosenick, L., Zarabi, H., et al. (2011). Amygdala circuitry mediating reversible and bidirectional control of anxiety. Nature 471, 358-362. doi: 10.1038/nature09820 
Vizzard, M. A. (2000). Increased expression of spinal cord Fos protein induced by bladder stimulation after spinal cord injury. Am. J. Physiol. Regul. Integr. Comp. Physiol. 279, R295-R305. doi: 10.1152/ajpregu.2000.279.1.r295

Vizzard, M. A., Erdman, S. L., and de Groat, W. C. (1996). Increased expression of neuronal nitric oxide synthase in bladder afferent pathways following chronic bladder irritation. J. Comp. Neurol. 370, 191-202. doi: 10.1002/(sici)10969861(19960624)370:2<191::aid-cne5>3.3.co;2-v

Wang, H. F., Shortland, P., Park, M. J., and Grant, G. (1998). Retrograde and transganglionic transport of horseradish peroxidase-conjugated cholera toxin B subunit, wheatgerm agglutinin and isolectin B4 from Griffonia simplicifolia I in primary afferent neurons innervating the rat urinary bladder. Neuroscience 87, 275-288. doi: 10.1016/s0306-4522(98)00061-x

Yoshimura, N., Bennett, N. E., Hayashi, Y., Ogawa, T., Nishizawa, O., Chancellor, M. B., et al. (2006). Bladder overactivity and hyperexcitability of bladder afferent neurons after intrathecal delivery of nerve growth factor in rats. J. Neurosci. 26, 10847-10855. doi: 10.1523/JNEUROSCI.3023-06.2006

Yoshimura, N., Seki, S., Erickson, V., Erickson, K., Kassotakis, L., Novakovic, S., et al. (2001). Suppression of the tetrodotoxin-resistant sodium channel (PN3/SNS): a possible new treatment for bladder pain. Urology 57, 116-117. doi: 10.1016/s0090-4295(01)01061-5

Yoshimura, N., White, G., Weight, F. F., and de Groat, W. C. (1996). Different types of $\mathrm{Na}+$ and A-type $\mathrm{K}+$ currents in dorsal root ganglion neurones innervating the rat urinary bladder. J. Physiol. 494, 1-16. doi: 10.1113/jphysiol. 1996.sp021471

Yoshiyama, M., Mochizuki, T., Nakagomi, H., Miyamoto, T., Kira, S., Mizumachi, R., et al. (2015). Functional roles of TRPV1 and TRPV4 in control of lower urinary tract activity: dual analysis of behavior and reflex during the micturition cycle. Am. J. Physiol. Renal Physiol. 308, F1128-F1134. doi: 10.1152/ajprenal.00016.2015

Zhong, F., Christianson, J. A., Davis, B. M., and Bielefeldt, K. (2008). Dichotomizing axons in spinal and vagal afferents of the mouse stomach. Dig. Dis. Sci. 53, 194-203. doi: 10.1007/s10620-007-9843-Z

Conflict of Interest Statement: The authors declare that the research was conducted in the absence of any commercial or financial relationships that could be construed as a potential conflict of interest.

Copyright (c) 2018 DeBerry, Samineni, Copits, Sullivan, Vogt, Albers, Davis and Gereau. This is an open-access article distributed under the terms of the Creative Commons Attribution License (CC BY). The use, distribution or reproduction in other forums is permitted, provided the original author(s) and the copyright owner are credited and that the original publication in this journal is cited, in accordance with accepted academic practice. No use, distribution or reproduction is permitted which does not comply with these terms. 